\author{
Ali A. A. Rawabdeh ${ }^{1}$ \\ Rami M. Tubaishat
}

\section{THE WORLDWIDE SETTING OF HIGHER EDUCATION QUALITY ENHANCEMENT ACTIVITIES COUPLED WITH KPIS: AN OPEN COMPOSITION FOR YARMOUK UNIVERSITY IN JORDAN}

\begin{abstract}
The Higher Education within the glob presently a day confront an unused time due to changes within the way individuals see higher education educate. They have achieved numerous add-up to quality profile in terms of quantity and quality at programs and graduate levels in the world. Desires for ways better execution in terms of instructing and creating competent college graduates are expanding. In the meantime, universities strike to expand certain avances at the international level in terms of expanding vertically and horizontally to offer a solid high quality and progressed learning opportunities to satisfy client needs. To achieve this, higher education arrangements higher education policy makers ought to make such an environment in which agencieshas pride in their work and keep up with new developments and changes.
\end{abstract}

Keywords: KPI, educational quality, Jordan

\section{Introduction}

The Higher Education within the glob presently a day confront an unused time due to changes within the way individuals see higher education educate. They have achieved numerous add-up to quality profile in terms of quantity and quality at programs and graduate levels in the world. Desires for ways better execution in terms of instructing and creatingcompetent college graduates are expanding. In the meantime, universities strike to expand certain avances at the international level in terms of expanding vertically and horizontally to offer a solid high quality and progressed learning opportunities to satisfy client needs. To achieve this, higher education arrangements higher education policy makers ought to make such an environment in which

\footnotetext{
${ }^{1}$ Corresponding author: Ali Ahmad Awwad Rawabdeh Email: ali.rawabdeh@yu.edu.jo
}

agencieshas pride in their work and keep up with new developments and changes.

Quality is a slippery trait of values, which cannot be easily measured or quantified. Quality assurance refers to a run of audit strategies designed to protect scholastic guidelines and advance learning openings for students of satisfactory quality. Quality enhancement is taking ponder steps to bring about continual improvement within the viability of the learning involvement of students (AACSB, 2016; and,African Union, (2015),

The quality assurance development and enhancement in higher education directly stand as one of the most excellent needs of cutting-edge higher education systems in the globe. In the recent past decades, various countries in the world have established national quality assurance bodies in arrange 
to ensure that higher education has no compromise on quality(ElassyNoha, 2015), Due to the weight of internationalization and globalization higher education systems have had to benchmark their quality assurance criteria from the worldwide developed higher education system to orchestrate quality affirmation and legitimacy. There are different components influencing the establishment of quality assurance in higher education appeared up to be around the world in nature, be that because it may, some of the component are incomprehensible to miss to Jordan.

\section{Problem statement}

Yarmouk University still have developing intrigued in creating of quality systems as a means of organizational change through the perfection of key processes. It looks to grasp the quality management philosophy and incorporate the universal quality assurance standards as an integral part of its vital objectives, since of competition and orders for responsibility by accreditation, to focus on improving the quality of scholastic and other services. So that, this article designs the responsible system of quality improvement and enhancement to coordinate and control all forms to guarantee national accreditation agencies and other statutory bodies necessities, internal and external clients, stakeholders and imminent employers are met(Haris, Ikhfan, 2013); and, AACSB, 2016).

Because it gets to be non-voluntary accreditation for both organizational and programs of higher education institution, Yarmouk, in a time of worldwide competition, this article will bring together the issues and proposed arrangements of quality improvement and enhancement coupled with Key Performance Indicators (KPIs) to most genuine challenges confronting local and universal accreditation. (Cremonini, et al, 2012; AAU, 2015)
Yarmouk Colleges ought to learn from the all-inclusive authorized organization i.e., QAA etc. barely to accomplish their key objective i.e., advancing overall objective; advancing environment of higher education; make the portion of higher education i.e., teaching-learning- assessmentsmart works out; and, actualize universal best sharpen strategies over periodic studies and scientific research. The middle of these operational plans will incorporate reengineering of quality frameworks in consonance with around the world criteria.

\subsection{Aims and Objectives}

This article aimed at prescribing distinctive ways of appraising and enhancing the quality of the higher education institutions and making them more critical to social and economic demands; lengthening get to higher education; increasing number of students, as a rule within the confront of diminishing unit cost; guaranteeing comparability of course of action and strategies, interior and between higher education institutions, counting universal comparisons.

\subsection{Research Questions}

Is the culture solid of quality? Does the organization design strengthen or prevent quality achievement? Is quality recognized as an issue? Is the focus right for accomplishing quality? Is the mind-set allencompassing or reductionist?

\subsection{Methods}

Data for this exploratory report were gotten by recommended of see of scattered surface utilizing characterized watchwords and electronic databases were looked covering wide range period of more than 15 a long time commencing the early of 2000s, using 


\section{Intermational Qualilty Conference}

$\mathrm{QUAMUTY}$ RIESIEAIRCI-

content words and passage terms: Jordan, Arab world, higher education, total quality management framework, quality assurance, quality control, higher education reform, quality audit. In expansion, reference list of disseminated studies was looked physically for present articles. To play down disposition and progress the value of this report researchers conducted exhaustive examination of existing literature by implies of individual contact with senior officers at higher education authorities, government workplaces, and national quality and accreditation divisions and key universal sources i.e., QAA (QAA), AACSB, and local sources such as the Ministry of Higher Education (MOHE), , Jordan University and Jordan University of Science and Technology. Qualified studies were those that centered on the Jordanian higher education delivery and control systems. Avoided studies were those that centered on extensive outline and replicated considers. Two analysists (AR, RT) autonomously screened the titles and unique of the recognized thinks about and duplications were outside. Studies considered qualified for full content screening were recovered for full review. The analysists autonomously evaluated the papers for qualification and quality and met to resolve any discrepancy with respect to qualification and/or quality. The key highlights of the considers were summarized, tables and pertinent portrayal of KPIs and area of enhancement frameworks was carried out.Despite the overwhelming endeavors to set up the quality frameworks in Yarmouk University since 2012, the researchers have done a quick "SWOT" analysis and find essential (not compelled to) preeminent hindrances to quality among which of: framework and procedures, culture, organization design, administration perspectives. Systems and methodologies: quelling the intrigued of quality; Culture: states of mind, values and convictions.

As a consider action report the researchers concur to construct the body of the research about on the bases of target industry higher education subsystems identification in Jordan which has certain demographic characteristics, briefing almost the higher education and quality systems with the focus on development and enhancement trends with the focus on government funded services to be compared at neighborhood, reginal and international levels (ANQAHE, 2012).

\section{Implications of higher education placement and enhancement programs}

There is a need for Yarmouk University to be crucial in framing quality frameworks and the practice of the same and guaranteeing that esteem in all services provided. This will empower Yarmouk to adjust its foci of quality administration to realized advancement and improvement in conjunction with around the worldadaptable components of present-day higher education directions. In doing so, this article will offer to Yarmouk university a comprehensive tracs of standardized quality advancements and enhancement operational exercises and weigh them on the scale of quality assurance to ensure a key adjustment required for improved quality

\subsection{Limitations of the study}

It is anticipated that there will a fewimpediments in this study among of which of the followings: This study will be restricted to public higher education entity in north of Jordan. It will examine the most causes of blocking the advance of improving and modernizing the quality profile to meet the local and international requirements. It will may not incorporate the specifiedexaminations of eight standards of the local accreditation officein terms of 
measuring all of the exhibitions with agreement to the furnished standers and planning of remedialactivities and create the advancement and enhancement bundles with the required KPIs.

\section{References}

Kusi-Sarpong, S., Varela, M. L., Putnik, G., Avila, P., \& Agyemang, J. (2018). Supplier evaluation and selection: a fuzzy novel multi-criteria group decision-making approach. International Journal for Quality Research, 12(2), 459-486. doi: 10.18421/IJQR12.02-10

AACSB International - The Association to Advance Collegiate Schools of Business, (2016), Eligibility Procedures and Accreditation Standards for Business Accreditation, Engagement, Innovation, Impact, South Harbour Island Blvd.,, Tampa: USA. www.aacsb.edu

AAU Association of Arab Universities, (2015), Guide for Quality Assurance of Academic Programs at Arab Universities Faculties, $2^{\text {nd }}$ Edition, Association of Arab Universities, Secretariat-General, Amman - Jordan: At : ACE American Council on Education, (2012), Assuring Academic Quality in the 21st Century: Self-Regulation in a New Era A Report of the ACE National Task Force on

Institutional Accreditation, American Council on Education, Leadership and Advocacy.

African Union, (2015), "African Standards and Guidelines for Quality Assurance in Higher Education (ASG-QA)," HAQAA Initiative, available at: http://hdl.handle.net/2445/126939

Ann Katherine Isaacs, (2014), "Building a Higher Education Area in Central Asia: challenges and prospects), Tuning Journal for Higher Education, University of Deusto. Volume 2, Issue No. 1, pp: 31-58

ANQAHE Arab Network for Quality Assurance in Higher Education, (2012), Survey of Quality Assurance and Accreditation in Higher Education in the Arab Region- second scoping study, Global Initiative for Quality Assurance Capacity Building (GIQAC), World Bank and implemented by the UNESCO.

ElassyNoha, (2015), "The concept of Quality, Quality Assurance and Quality Enhancement", Quality Assurance in Education, Vol. 23 Issue: 3, pp.250-261, https://doi.org/10.1108/QAE11-2012-0046,

Haris, Ikhfan, (2013), Assessment on the implementation of internal quality assurance at higher education (An Indonesian Report), Journal of Educational and Instructional Studies in the World, Volume: 3 Issue: 4 Article: 06 ISSN: 2146-7463

HFE (Alhussein Fund for Excelelnce, (2005), Quality Assessment and Enhancement for Higher Education in Jordan, the Subject Review Handbook, available at: https://www.husseinfund.jo/?q=en/node/18

Kehm, Barbara M., (2013), The German System of Quality Assurance and Accreditation in Higher Education, Societ aeditriceilMulino, Bologna. Tuttiidirittisonoriservati. Per altreinformazionisivedahttps://www.rivisteweb.it

Kanishka Jayasuriya, (2015), Transforming the Public University: Market Citizenship and Higher Education Regulatory Projects, Through A Glass Darkly, ANU Press, http://www.jstor.org/stable/j.ctt13wwvss.12.

Kohoutek, Jan. (2009), Implementation of the Standards and Guidelines for Quality Assurance in Higher Education in the Central and East-European Countries - Agenda Ahead, 
UNESCO-CEPES Studies on Higher Education, outcome Research Plan, Tertiary Education in the Knowledge Society of the Centre for Higher Education Studies, Prague, Czech Republic.

Maria J. Rosa; Claudia S. Sarrico; and Alberto Amara , (2012), Implementing Quality management Systems in Higher Education Institutions, InTech, Available from: http://www.intechopen.com/books/quality-assurance-andmanagement/implementing-qualitymanagement-systems-in-higher-education-institutions.

Mayunga H.H. Nkunya, (2014), Principles and Guidelines for Quality Assuarnce in Higher Education in East Africa, Inter-University Council for East Africa, available at: http://iucea.org/eahea1/wp-content/uploads/bsk-pdf-

manager/Principles_and_Guidelines_for_Quality_AssuranceJune_in_Higher_Education_201 4_10.pdf

NCAAA National Commission for Accreditation and Assessment, (2015), Handbook for Quality Assurance and Accreditation in Saudi Arabia PART 1, 2, 3, The system for quality Assurance and Accreditation, Saudi Arabia: at http://www.ncaaa.org.sa/en/Releases/Pages/Handbooks.aspx

(NIAD-UE National Institution for Academic Degree and University Evaluation Quality Assurance System in Higher Education, Japan:

(2009),

At http://www.niad.ac.jp/n_kokusai/info/japan/overview_jp_e.pdf

Nigel Palmer.(2015), The Modern University and its Transaction with Students, Through A Glass Darkly, in The Social Sciences Look at the Neoliberal University, ANU Press: http://www.jstor.org/stable/j.ctt13wwvss.14

PaliulisNarimantasKazimieras, LabanuskisRimvydas, (2015), Benchmarking as an Instrument for Improvement of Quality Management in Higher Education, Business, management and Education, 13(1): 140-157. doi:10.3846/bme.2015.220

Peter Knight, (2006), "Quality Enhancement and Educational Professional Development", Journal in Higher Education; Volume, 12, Issue 1, pp:29-40, https://doi.org/10.1080/13538320600685123

Peter van der Hijden, (2014), "Modernizing higher education: the emergence of European public goods", Tuning Journal for Higher Education, University of Deusto. Volume 2, Issue No. 1, pp: 19-29

Podger, Andrew (2015), Innovation in the public sector: beyond the rhetoric to a genuine 'leading culture'. In the Managing under Austerity, Delivering Under Pressure, Performance and Productivity in Public Service, ANU Press: http://www.jstor.org/stable/j.ctt19893n9.12

QAA Quality Assurance Agency for Higher Education (QAA). (2016). safeguarding standards and improving the quality of UK higher education: The Quality Assurance Agency for Higher Education. Reviews and reports. Available at: http://www.qaa.ac.uk/reviewsreports/provider?UKPRN=10037353\#.WdqKNWiCxdg

UQAIB University Quality Assurance International Board, (2016), Quality Assurance Manual, Version 2.5, Knowledge and Human Development Authority, Dubai, United Arab Emirates, KHDA website, www.khda.gov.ae:

https://www.khda.gov.ae/CMS/WebParts/TextEditor/Documents/UQAIB_EN.pdf 
Ali A. A. Rawabdeh

Yarmouk University, Faculty

of Medicine, Department of

Biomedical Sciences/Health

Services Management

Program

Irbid,

Jordan

ali.rawabdeh@yu.edu.jo

\section{Rami M. Tubaishat}

Yarmouk University, Faculty

of Economics and

Administrative Sciences,

Public Administration

Department

Irbid,

Jordan

rami.tbaishat@yu.edu.jo 